\title{
Strategi penerapan kemahiran abad ke-21 dalam latihan guru prasekolah
}

\author{
Strategies to Implement $21^{\text {st }}$ Century Skills in Preschool Teachers Training
}

\author{
Syed Lamsah Syed Chear ${ }^{1}$, Melor Md Yunus ${ }^{2}$
}

Fakulti Pendidikan dan Sains Sosial, Universiti Selangor, Bestari Jaya, Selangor, Malaysia ${ }^{1}$ Fakulti Pendidikan, Universiti Kebangsaan Malaysia, Bangi, Selangor, Malaysia ${ }^{2}$

\author{
syedlamsah@unisel.edu.my¹,melor@ukm.edu.my²
}

DOI: https://doi.org/10.37134/saecj.vol8.no1.1.2019

Received: 08 March 2019; Accepted: 10 May 2019; Published: 03 June 2019

\begin{abstract}
ABSTRAK
Masyarakat dunia semakin terkesan dengan impak Revolusi Industri 4.0, dan pendidikan tinggi dijadikan sandaran untuk memperlengkapkan pengetahuan, kemahiran dan personaliti graduan. Artikel ini membincangkan secara konseptual amalan pengajaran dan pembelajaran (PdP) dalam program prasekolah di universiti swasta. Penggunaan teknologi maklumat dan komunikasi (TMK) telah mempermudah dan menjadikan aktiviti PdP bertambah menarik. Namun, perlu disedari TMK adalah sebagai platform berbanding objektif akhir untuk menerapkan kemahiran abad ke-21 dalam kalangan graduan. Strategi PdP yang dilaksanakan memfokus kepada objektif untuk memperluas skop kerjaya melalui pendekatan pengajaran terbalik, atas talian, kolaborasi dan koperatif, terbuka dan merentasi kurikulum serta penilaian holistik yang bertujuan melahirkan graduan yang peka kepada sekeliling, cerdas sosial, bijak berfikir, kemahiran silang budaya, celik huruf kepada media baru, terbuka minda, dan berupaya mengurus pengetahuan dan kerjasama maya. Penerapan kemahiran abad ke-21 kepada guru pelatih melalui pelbagai strategi PdP dapat mengangkat kerjaya guru prasekolah.
\end{abstract}

Kata kunci: latihan guru prasekolah, strategi pengajaran dan pembelajaran, kemahiran abad ke-21

\begin{abstract}
Communities throughout the world are increasingly impressed with the impact of the Industrial Revolution 4.0 and higher education hold an indisputable responsibility to equip graduates with the $21^{\text {st }}$ century of knowledge, skills and attitudes. This article discusses the conceptual basis of teaching and learning (T\&L) practice within the preschool program at a private University. Information and communication technology (ICT) without doubt facilitating and resulting in more exciting T\&L activities. However, the main objective of using ICT is to develop $21^{\text {st }}$ century life skills among graduates. The implemented teaching strategies are online, collaborative and cooperative learning, open and cross-curriculum activities as well as holistic assessment. This strategies will produce graduates who are sense-making, social intelligence, novel and adaptive thinking, cross-cultural competency, new-media literacy, transdisciplinarity, design mindset, cognitive load management and demonstrate presence as a member of a virtual team. These will widen and lift up the career of preschool graduates.
\end{abstract}

Keywords: training for preschool teachers, teaching and learning strategy, $21^{\text {st }}$ century 


\section{PENGENALAN}

Isu-isu berkaitan globalisasi, pengantarabangsaan, Revolusi Industri 4.0 dan impaknya terhadap perubahan gaya hidup masyarakat menuntut perubahan besar terhadap kurikulum pendidikan (Florea \& McGrath, 2014; Kress, 2010; Luxon \& Peelo, 2009; Misra, 2012).

Strategi pengajaran dan pembelajaran (PdP) bagi abad ke-21 semakin kompleks dan rumit (Scott, 2015). Pengaruh internet dan media sosial turut menimbulkan dilema dalam kalangan pendidik dan ibu bapa (Leung \& Lee, 2011). Kurikulum masa kini menumpu kepada usaha untuk melengkapkan para pelajar dengan pelbagai kemahiran bagi menghadapi abad ke-21 (Alismail \& McGuire, 2015). Pengajian global serta komponen kursus kemahiran insaniah mula mendapat perhatian dan diperkenalkan di institusi pendidikan tinggi (Sparapani, Perez, Gould, Hillman, \& Clark, 2014).

Latihan perguruan menjadi agenda terpenting kerana ia menentukan kejayaan pelaksanaan sistem pendidikan di sekolah (Azam, Fauzee \& Daud, 2014). Artikel ini membincangkan secara konseptual pendekatan PdP bagi menerap kemahiran abad ke-21 dalam latihan guru prasekolah di universiti swasta. Latar belakang institusi yang pelbagai serta syarat kelayakan masuk yang longgar menjadikan program latihan guru prasekolah di institusi swasta terdedah kepada kepincangan dan gagal menghasilkan guru yang diperlukan untuk masa hadapan. Ketidakupayaan staf akademik untuk mengenal pasti objektif sesuatu amalan pengajaran serta keengganan guru pelatih untuk menerima inovasi dalam pengajaran menimbulkan tanda tanya terhadap kejayaan pendidikan berasaskan hasil pembelajaran (OBE) yang diharapkan.

\section{Objektif Pendidikan dan Hasil Pembelajaran Program Prasekolah}

Matlamat program pendidikan awal kanak-kanak adalah untuk melengkapkan pelajar dengan pengetahuan, kemahiran dan kompetensi untuk mereka menjadi profesional dan bekerja di latar persekitaran pendidikan awal kanak-kanak. Berdasarkan Agensi Kelayakan Malaysia (2014), terdapat lapan domain hasil pembelajaran, iaitu pengetahuan, kemahiran praktikal; kemahiran dan tanggungjawab sosial; nilai, sikap dan profesionalisme; kemahiran komunikasi, kepimpinan dan kerja berpasukan; kemahiran penyelesaian masalah dan kemahiran saintifik; kemahiran pengurusan maklumat dan pembelajaran sepanjang hayat; dan kemahiran mengurus dan keusahawanan. Kurikulum pembelajaran di Institut Pengajian Tinggi (IPT) turut memberi penekanan kepada pembangunan kemahiran generik dalam kalangan pelajar, iaitu kemahiran berkomunikasi; pemikiran kritis dan kemahiran menyelesaikan masalah; kemahiran kerja berpasukan; pembelajaran berterusan dan pengurusan maklumat; kemahiran keusahawanan; etika dan moral profesional; dan kemahiran kepimpinan (KPT, 2010).

Kajian Lidija, Renata, dan Sanja (2014) menunjukkan hubungan komunikasi antara guru dengan guru pelatih prasekolah mempengaruhi keupayaan mereka terhadap kemahiran pembelajaran sepanjang hayat dan inginkan perubahan. Pendidikan formal, pengetahuan tentang kanak-kanak dan bimbingan berterusan menghasilkan perkhidmatan asuhan dan didikan awal kanak-kanak yang berkualiti serta keakraban antara kanak-kanak dengan guru (Fuligni, Howes, Lara-Cinisomo, \& Karoly, 2009). Sharon (2018) mendapati sistem mentoran dan latihan berorientasikan suasana sebenar kelas pengajaran meningkatkan tahap pengetahuan dan penyampaian kurikulum serta perkembangan profesional guru prasekolah apabila memasuki tahun pertama perkhidmatan. Mereka bermotivasi dan berjaya mencapai harapan peribadi walaupun kepuasan kerja didapati menurun. Pemerhatian berterusan menunjukkan 
berlaku penurunan aktiviti pembelajaran dan pencapaian hasil pembelajaran apabila semakin lama mereka berkhidmat. Kajian-kajian ini mencadangkan kualiti perkhidmatan prasekolah akan tercabar sekiranya guru pelatih prasekolah terlalu bergantung kepada guru semasa dalam latihan, dan gagal menghayati proses pembelajaran yang diharapkan. Ini menyebabkan mereka tidak dapat menyesuaikan diri dengan perubahan dan cabaran apabila memasuki perkhidmatan sekaligus mempengaruhi pencapaian hasil pembelajaran.

\section{Impak Revolusi Industri 4.0}

Revolusi Industri 4.0 dipacu oleh beberapa senario yang berlaku di seluruh dunia seperti peningkatan melampau umur populasi dunia akibat daripada tahap kesihatan dan keselamatan yang semakin meningkat, kebergantungan manusia kepada sistem dan mesin pintar, pengumpulan data setiap aktiviti untuk proses pembuatan keputusan akan datang, kaedah berkomunikasi cara baharu, struktur mega organisasi yang bersifat multi-nasional dan sistem dunia yang semakin terangkai antara satu sama lain (Anna, Devin, \& Marina, 2011). Generasi akan datang perlu memiliki pelbagai kemahiran untuk menyesuaikan diri, seperti peka kepada persekitaran, cerdas sosial, bijak dan mahir berfikir, kemahiran silang-budaya, berfikir seperti komputer, celik kepada media baharu, multidisiplin, minda terbuka, mengurus pengetahuan, dan berupaya untuk menjalin kerjasama maya (Penprase, 2018). Para pendidik, graduan dan ibu bapa dijangka akan berhadapan dengan pelbagai isu dalam menghadapi Revolusi Industri 4.0, antaranya ialah isu-isu berkaitan ekonomi dunia dan impaknya kepada pertumbuhan ekonomi negara, dan gejala sosial dalam masyarakat yang semakin tertekan termasuk isu-isu kekeluargaan akibat daripada perubahan yang berlaku di sekeliling (Roland Berger, 2016).

Cabaran utama graduan adalah untuk memulakan kerjaya apabila mereka menamatkan pengajian di universiti. Forum Ekonomi Dunia (World Economic Forum [WEF], 2016) mengunjurkan akan berlaku perubahan latar belakang keperluan pekerjaan bermula pada tahun 2021. Penguncupan terbesar dijangkakan berlaku dalam sektor pekerjaan yang bersifat pentadbiran pejabat, perundangan dan kewangan termasuk pendidikan dan latihan, manakala peningkatan keperluan tenaga kerja adalah dalam bidang yang berkaitan dengan kejuruteraan, seni bina, pengkomputeran dan matematik. Perubahan ini adalah didorong oleh penggunaan robotik dan 'artificial intelligence' sebagai gantian tenaga manusia. Tenaga kerja pada masa hadapan sama ada seorang guru mahupun doktor perubatan perlu memiliki kemahiran tinggi seperti 'statistical analysis', 'data mining' dan 'cloud and distributed computing' untuk terus diperlukan oleh industri.

\section{STRATEGI MENERAPKAN KEMAHIRAN ABAD KE-21 DALAM LATIHAN GURU PRASEKOLAH}

Penerapan kemahiran abad ke-21 dalam program latihan guru serta kemampuan mereka untuk mengaplikasi pengetahuan dan kemahiran tersebut di sekolah adalah merupakan satu keperluan penting (AACTE, 2010). Pendekatan pengajaran terbaik di universiti adalah kaedah bercampur, iaitu berpusatkan pelajar dan pensyarah, perancangan pengajaran dan kesediaan untuk mengikuti pembelajaran (Bidabadi, Isfahani, Rouhollahi, \& Khalili, 2016). Implementasi untuk menerapkan kemahiran abad ke-21 dalam kurikulum merupakan sesuatu yang mencabar dan ia lebih mudah dilaksanakan melalui kursus-kursus yang memfokus kepada objektif membentuk kemahiran belajar dan inovasi dalam kalangan pelajar, kursus teknologi maklumat dan media, 
manakala kursus-kursus sokongan lain dikaitkan kepada kemahiran hidup dan kerjaya (Wrahatnolo \& Munoto, 2018).

Pedagogi pengajaran yang sering diamalkan adalah seperti arahan langsung, kuliah interaktif, demonstrasi, permodelan, perbincangan, simulasi, penulisan jurnal, penyoalan, temu bual, pembelajaran berasaskan projek, pembelajaran koperatif termasuk menggunakan ujian objektif dan kuiz, tugasan penulisan esei reflektif dan pemerhatian (Lunderberg, 2016). Kemahiran berkomunikasi merupakan gerbang kemahiran untuk menguasai kemahirankemahiran lain yang lebih kompleks seperti kemahiran berfikir, menyelesai masalah, mengurus tekanan, pengambilan risiko di samping dapat memastikan kejayaan penyampaian maklumat dan pembinaan hubungan sesama manusia. Komunikasi berkesan membuka ruang kepada keupayaan untuk berkerja dalam kumpulan serta dapat menentukan kredibiliti maklumat yang disampaikan. Implementasi menerapkan kemahiran abad ke-21 dalam pengajaran terutamanya kuliah yang bersaiz besar memerlukan strategi PdP yang dirancang dan sistematik agar tiada pelajar yang terpinggir dan gagal menguasai hasil pembelajaran yang ditetapkan.

Pendekatan pengajaran program prasekolah sewajarnya perlu memfokus kepada perluasan skop kerjaya melalui amalan kuliah terbalik dan atas talian, pembelajaran terbuka dan merentasi kurikulum, pembelajaran secara kolaboratif dan koperatif, dan penilaian secara holistik. Rubrik bagi mengaitkan strategi pengajaran dan kemahiran-kemahiran abad ke-21 ditunjukkan dalam Jadual 1 berikut;

Jadual 1: Rubrik Strategi Pengajaran dan Terapan Kemahiran Abad Ke-21

\begin{tabular}{|c|c|c|c|c|c|c|}
\hline \multirow{2}{*}{$\begin{array}{c}\text { Kemahiran-kemahiran abad ke-21 yang } \\
\text { diterapkan dalam pengajaran. }\end{array}$} & \multicolumn{6}{|c|}{ Strategi Pengajaran dan Pembelajaran } \\
\hline & \multicolumn{6}{|c|}{ 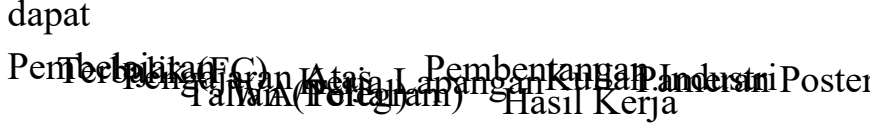 } \\
\hline Peka kepada persekitaran. & & & $\checkmark$ & & $\checkmark$ & $\checkmark$ \\
\hline Cerdas sosial. & & & $\checkmark$ & & $\checkmark$ & $\checkmark$ \\
\hline Bijak dan mahir berfikir. & & & $\checkmark$ & $\checkmark$ & & $\checkmark$ \\
\hline Kemahiran silang budaya. & & & $\checkmark$ & & & \\
\hline Berfikir seperti komputer. & $\checkmark$ & $\checkmark$ & & & & \\
\hline Celik huruf kepada media baru. & $\checkmark$ & $\checkmark$ & & & & \\
\hline Multidisiplin & & & $\checkmark$ & $\checkmark$ & $\checkmark$ & \\
\hline Minda terbuka. & $\checkmark$ & $\checkmark$ & & & $\checkmark$ & $\checkmark$ \\
\hline Mengurus pengetahuan. & $\checkmark$ & $\checkmark$ & & $\checkmark$ & $\checkmark$ & $\checkmark$ \\
\hline Menjalin kerjasama maya. & $\checkmark$ & $\checkmark$ & & & & \\
\hline
\end{tabular}

\section{Memperluas Skop Kerjaya}


Kemahiran sosial seperti sikap positif, komunikasi berkesan, dan bekerja efektif dalam kumpulan sering dikaitkan kepada ciri-ciri pekerja yang dikehendaki oleh organisasi dan syarikat multinasional (Cimatti, 2016). Kurikulum yang bertujuan mendedahkan pelajar kepada persekitaran kehidupan masa hadapan semakin diberi perhatian (Penttinen, Skaniakos \& Lairio, 2013). Keupayaan graduan untuk meneroka peluang pekerjaan merupakan antara faktor utama yang membantu mereka menyesuaikan diri (Guan et al., 2013). Strategi institusi mendedahkan para pelajar kepada kemahiran pengurusan kerjaya memberi faedah langsung kepada fakulti untuk membina jaringan industri serta meningkatkan kebolehpasaran graduan (Jackson \& Wilton, 2016).

Menurut Petre (2015), terdapat pelbagai sumber motivasi bagi seseorang memilih kerjaya sebagai guru prasekolah, walaupun ianya sukar ditentukan. Kehadiran guru prasekolah lelaki turut menimbulkan pelbagai tanggapan (Sumsion, 2000). Bidang kerjaya graduan prasekolah adalah cukup luas dan tidak sepatutnya ukuran kebolehpasaran mereka dihadkan kepada keterlibatan sebagai guru atau menjadi pengusaha taska dan tadika. Pengalaman pembelajaran graduan prasekolah di IPT perlu mendedahkan mereka kepada skop kerjaya yang lebih luas, iaitu tidak terhad kepada bidang penjagaan dan pendidikan awal kanak-kanak semata-mata. Peluang kerjaya graduan prasekolah adalah lebih terbuka di sektor swasta termasuk sekolah-sekolah antarabangsa serta industri hiliran seperti penerbitan bahan pembelajaran, inovasi dalam menghasilkan alat bantu mengajar, urus-acara, khidmat rundingan keluarga, dan pusat hiburan akademik berkonsepkan keluarga. Namun, perlu disedari bahawa pendekatan pengajaran yang terlalu berorientasikan kepada kebolehpasaran graduan dikhuatiri akan objektif pembelajaran untuk mendalami ilmu (Speight, Lackovic \& Cooker, 2013). Pada masa yang sama, keupayaan ahli akademik untuk memahami prospek kerjaya masa hadapan juga penting sejajar dengan OBE.

\section{Pembelajaran Terbalik (Flipped Classroom) dan Atas Talian}

Pembelajaran terbalik (flipped classroom) semakin meluas dilaksanakan sesuai dengan tuntutan agar pelajar menguasai kemahiran abad ke-21 (O'Flaherty \& Phillips, 2015). Walaupun penggunaan teknologi komputer di prasekolah mendapat reaksi yang berbeza daripada guru (Lindahl \& Folkesson, 2012), tetapi kajian Mortensen dan Nicholson (2015) menunjukkan ia mampu meningkatan pencapaian akademik. Kurikulum latihan guru pada masa kini perlu disesuaikan dengan perubahan semasa (Hao \& Lee, 2016). Kursus Terbuka Atas Talian secara Besar-Besaran versi 2.0 atau lebih dikenali sebagai MOOC 2.0 telah dilancarkan di beberapa negara dan ini akan mengubah lagi landskap pembelajaran atas talian yang sedia ada (Sharma, 2017).

Wajah pendidikan tinggi kini telah berubah secara dramatik. Guru abad ke-21 dan pengajaran di prasekolah tidak lagi semata-mata untuk menyampaikan maklumat. Dalam era maklumat di hujung jari, latihan guru prasekolah perlu didedahkan dengan kemahiran untuk mengakses maklumat, menyaring dan menyimpan maklumat dengan cara paling selamat. Flipped Classroom adalah strategi pengajaran yang menterbalikan kaedah pembelajaran tradisional melalui gabungan pembelajaran iaitu maklumat kursus disampaikan di luar waktu kuliah menggunakan aplikasi atas talian. Jika dahulu ianya dianggap sebagai kerja rumah, kini ia mendorong pembelajaran kendiri di mana setiap pelajar dikehendaki mengambil inisiatif untuk bekerjasama dalam kumpulan bagi membuat penyelidikan daripada capaian maklumat yang dibekalkan. Pembelajaran aktif berlaku apabila para pelajar hadir kuliah dan terlibat secara langsung dalam aktiviti perbincangan, pembentangan atau demonstrasi kemahiran bersama rakan sekuliah. 
Tiada lagi amalan "spoon-feed", sebaliknya pensyarah bertindak sebagai moderator dalam proses pembelajaran. Penyepaduan teknologi dalam aktiviti pembelajaran seperti pembelajaran atas talian dan pembelajaran terbalik diharapkan dapat mengasah kebolehan guru prasekolah daripada aspek kebertanggungjawab, keupayaan menganalisis, memimpin dan saling bekerjasama, bekerja berkumpulan, dan menyelesaikan masalah secara saintifik yang diperlukan untuk pekerjaan masa hadapan. Pendekatan pembelajaran terbalik dan atas talian menggunakan portal e-learning, whatsapp dan telegram web dapat dikaitkan kepada startegi untuk melengkapkan graduan dengan kemahiran abad ke-21, iaitu; (i) keupayaan untuk menilai secara kritikal dan membangunkan kandungan yang menggunakan bentuk media baharu dan berupaya memanfaatkan media ini bagi komunikasi persuasif; (ii) keupayaan untuk menterjemahkan sebanyak mungkin maklumat kepada konsep-konsep abstrak dan memahami taakulan berasaskan data; dan (iii) keupayaan untuk memilih dan menapis maklumat untuk kepentingan, serta memahami bagaimana memaksimumkan fungsi kognitif menggunakan pelbagai alat dan teknik.

\section{Pembelajaran secara Koperatif dan Kolaboratif}

Pembelajaran secara kolaborasi, koperatif dan penyelesaian masalah adalah penting untuk menghadapi cabaran abad ke-21 (Davidson \& Major, 2014). Pembelajaran atas talian menggunakan telefon pintar memperluas capaian maklumat dan kemahiran berkolaborasi melalui peluang untuk berkerjasama dan mencari penyelesaian yang bersifat kreatif dan kritikal (Lee et al., 2016). Tugasan kumpulan merupakan antara pendekatan untuk menggalakkan pembelajaran koperatif dan kolaboratif dalam kalangan pelajar. Kursus-kursus tertentu mengkehendaki pelajar melakukan tugasan secara berkumpulan berbentuk kajian pasaran, khidmat rundingan peningkatan kualiti, dan soal selidik inovasi memerlukan para pelajar berhubung rapat dengan pengusaha-pengusaha tadika swasta. Aktiviti-aktiviti sebegini mendedahkan guru pelatih prasekolah kepada kemahiran literasi dan kebolehan untuk memahami konsep merentasi pelbagai disiplin; keupayaan untuk beroperasi dalam persekitaran budaya yang berbeza; kemahiran berfikir dan keupayaan membuat penyelesaian dengan memberi pelbagai cadangan yang berasaskan peraturan.

\section{Pembelajaran Terbuka dan Merentasi Kurikulum}

Permuafakatan universiti-komuniti tidak hanya terhad kepada aktiviti pengajaran, penyelidikan dan kerja sosial di universiti, tetapi turut mencakupi pelbagai konsep kerjasama di sekolah, organisasi dan masyarakat (Soska \& Butterfield, 2013). Pengurusan berkesan perkongsian dan peluang untuk menjana ilmu adalah sesuatu yang wajar dilakukan oleh universiti dan komuniti (Chile \& Black, 2015; McNall, Reed, Brown, \& Allen, 2009). Keterlibatan pelajar dalam proses pembelajaran bersama komuniti diketahui meningkatkan pencapaian hasil pembelajaran serta pembentukan personaliti pelajar (O’Connor, Lynch \& Owen, 2011). Pembelajaran bersama komuniti dibuktikan berjaya meningkatkan kemampuan kognitif pelajar serta amalan baik dalam masyarakat (Smith, Emmett \& Woods, 2008). Perkhidmatan internet seperti sistem jaringan sosial (SNS) menawarkan potensi tersendiri perkongsian maklumat antara universiti dan komuniti (Baruch \& Hershkovitz, 2012). Kejayaan permuafakatan universiti-komuniti dan impaknya kepada pembangunan sosial dan ekonomi bagaimanapun dipengaruhi oleh dasar dan amalan sesebuah universiti (Mtawa, Fongwa \& Wangenge-Ouma, 2016). 
Misi universiti pada masa kini adalah untuk menjana dan menyebarkan ilmu pengetahuan yang canggih untuk kebaikan pelajar, industri dan masyarakat. Operasi industri hari ini sangat dipengaruhi oleh peluang-peluang yang tercipta akibat daripada kemajuan teknologi internet dan ia mencakupi semua fungsi sektor perkilangan daripada penghasilan produk, penyampaian dan pembangunan perkhidmatan sehingga kepada pemasaran produkproduk baharu. Konsep pembelajaran secara koperatif diperluaskan kepada pembelajaran terbuka dengan pemain industri iaitu pihak-pihak yang berkepentingan dalam industri pendidikan awal kanak-kanak.

Universiti Selangor mengambil inisiatif menjemput para guru daripada pelbagai institusi prasekolah dan para usahawan untuk terlibat dalam pelbagai aktiviti pembelajaran di universiti. Ia meliputi program penasihatan, penilaian bahan peperiksaan termasuk juga aktiviti pembelajaran interaktif bersama pelajar melalui seminar, dan pameran hasil kerja. Ini diharapkan dapat mencetus idea-idea inovasi baik dalam kalangan pelajar, guru dan usahawan prasekolah. Pendekatan pembelajaran terbuka dengan pihak industri adalah untuk mendedahkan graduan kepada kemahiran pembelajaran maya yang diperlukan dalam abad ke21. Pekerja masa hadapan mesti berkeupayaan untuk bekerja dengan produktif, mendorong penglibatan, dan menunjukkan kehadiran sebagai ahli pasukan maya.

\section{Penilaian Holistik}

Pengukuran dan penilaian prestasi pelajar di IPT sering dikaitkan kepada pencapaian OBE. Kejayaan pelajar disusuli dengan pengijazahan kelas pertama, kelas kedua dan seterusnya. Kaedah penilaian yang seragam cenderung mengukur kelemahan dan bukan keistimewaan yang dimiliki oleh seseorang pelajar (Schuwirth \& Ash, 2013). Penilaian yang lebih holistik adalah diperlukan untuk memastikan graduan prasekolah turut menguasai kemahirankemahiran insaniah seperti sensitif, kecerdasan sosial dan kemahiran silang-budaya. Ketigatiga kemahiran ini merupakan antara 10 kemahiran yang perlu dimiliki oleh graduan abad ke21.

Kemahiran untuk berasa sensitif bermaksud mampu memahami sesuatu secara lebih bermakna berbanding penglihatan mata kasar atau yang dinyatakan. Kemahiran ini menjangkaui kemampuan mesin pintar yang dicipta untuk kerja-kerja yang bersifat rutin dan telah diformulakan. Peka dan logik akal membantu para pekerja untuk melahirkan suatu idea atau pandangan yang unik tetapi penting khususnya dalam proses pembuatan keputusan.

Kecerdasan sosial adalah merujuk kepada kebolehan seseorang untuk berhubung secara langsung dengan orang lain dengan lebih mendalam bagi merangsang reaksi dan interaksi yang dikehendaki. Pekerja sosial pintar boleh dengan cepat menilai emosi orang di sekelilingnya dan menyesuaikan perkataan, nada dan gerak isyarat mereka dengan sewajarnya. Kemahiran ini sangat penting untuk bidang pekerjaan yang memerlukan para pekerja untuk bekerjasama dan membina hubungan kepercayaan. Tambahan pula, operasi abad ke-21 yang bersifat global memerlukan sesebuah organisasi untuk bekerjasama dengan pelbagai kumpulan sasar yang berlainan latarbelakang. Kecerdasan sosial memberikan manusia atau golongan pekerja satu kelebihan yang tidak dimiliki oleh mesin pintar.

Graduan abad ke-21 juga perlu bersedia untuk bekerja dengan sebuah organisasi dalam persekitaran budaya yang berbeza. Kemahiran silang budaya kecekapan akan menjadi satu kemahiran yang penting bagi semua pekerja, bukan sahaja orang-orang yang telah beroperasi di persekitaran geografi yang pelbagai. Organisasi semakin melihat kepelbagaian sebagai pemacu inovasi. Kewujudan sesebuah organisasi yang berjaya dan inovatif adalah kombinasi 
daripada pelbagai peringkat umur, kemahiran, disiplin, dan gaya bekerja, dan pemikiran yang dibawa dan dikongsi secara bersama.

\section{KESIMPULAN}

Sesetengah IPT terutamanya di sektor swasta dibangunkan berdasarkan kepada infrastruktur teknologi dan keadaan sosial pada masa lalu. Landskap pendidikan kini telah berubah dan institusi pendidikan khususnya yang menawarkan program prasekolah harus segera mempertimbangkan cara untuk menyesuaikan diri dengan pantas akibat daripada perubahan tersebut. Antaranya; (i) meletakkan penekanan tambahan untuk membangunkan aspek kemahiran berfikir, berfikiran jauh, dan keupayaan membuat analisis yang kritikal; (ii) mengintegrasikan literasi media baharu ke dalam program pendidikan; (iii) memberi penekanan kepada aspek penting kemahiran insaniah seperti keupayaan untuk bekerjasama, bekerja dalam kumpulan, membaca isyarat sosial, dan bertindak balas (sensitif persekitaran); (iv) meluaskan skop pembelajaran untuk mempelbagai prospek kerjaya; dan (v) mengintegrasikan disiplin latihan yang membolehkan pelajar membangunkan kemahiran dan pengetahuan dalam pelbagai mata pelajaran.

\section{RUJUKAN}

AACTE. (2010). 21st century knowledge and skills in educator preparation. American Association of colleges of Teacher Education. Diperoleh daripada https://files.eric.ed.gov/fulltext/ED519336.pdf

Agensi Kelayakan Malaysia. (2014). Standard program pendidikan awal kanak-kanak. Petaling Jaya: Agensi Kelayakan Malaysia.

Alismail, H. A., \& McGuire, P. (2015). 21st Century standards and curriculum: Current research and practice. Journal of Education and Practice, 6(6). Diperoleh daripada www.iiste.org

Anna, D., Devin, F., \& Marina, G. (2011). Future works skills 2020. Palo Alto, CA: University of Phoenix Research Institute. Diperoleh daripada http://www.iftf.org/futureworkskills/

Azam, F., Fauzee, O., \& Daud, Y. (2014). A cursory review of the importance of teacher training. A case study of Pakistan. Middle-East Journal of Scientific Research, 21(6), 912-917. doi: 10.5829/idosi.mejsr.2014.21.06.21574

Baruch, A. F, \& Hershkovitz, A. (2012). A case study of Israeli higher education institutes sharing scholarly information with the community via social networks. Internet and Higher Education, 15(1), 58-68. https://doi.org/10.1016/j.iheduc.2011.08.003

Bidabadi, S. N., Isfahani, A. N., Rouhollahi, A., \& Khalili, R. (2016). Effective teaching methods in higher education: requirements and barriers. Journal of Advances in Medical Education \& Professionalism, 4(4), $170-178$.

Chile, L. M., \& Black, X. M. (2015). University-community engagement: Case study of university social responsibility. Education, Citizenship and Social Justice, 10(3), 234-253. doi: 10.1177/1746197915607278

Cimatti, B. (2016). Definition, development, assessment of soft skills and their role for the quality of organization and enterprises. International Journal for Quality Research, 10(1), 97-130. doi:10.18421/IJQR10.01-05

Davidson, N., \& Major, C. H. (2014). Boundary crossings: Cooperative learning, collaborative learning and problem-based learning. Journal on Excellence in College Teaching, 25, 7-55. Diperoleh daripada http://northweststate.edu/wp-content/uploads/files/BoundaryCrossings.pdf

Florea, S., \& McGrath, C. H. (2014). Governance and adaptation to innovative modes of higher education provision. Management of Sustainable Development, 6(1), 35-38. doi: 10.2478/msd-2014-0005 
Fuligni, A. S., Howes, C., Lara-Cinisomo, S., \& Karoly, L. (2009). Diverse pathways in early childhood professional development: An exploration of early educators in public preschools, private preschools, and family childcare homes. Journal of Early Education and Development, 20(3), 507-526. doi: 10.1080/10409280902783483

Guan, Y., Deng, H., Sun, J., Wang, Y., Cai, Z., Ye, L., \& Li, Y. (2013). Career adaptability, job search selfefficacy and outcomes: A three-wave investigation among Chinese university graduates. Journal of Vocational Behavior, 83(3), 561-570. doi: 10.1016/j.jvb.2013.09.003

Hao, Y., \& Lee, K. S. (2016). Teaching in flipped classrooms: Exploring pre-service teachers' concerns. Computers in Human Behavior, 57,250-260. doi: 10.1016/j.chb.2015.12.022

Jackson, D., \& Wilton, N. (2016). Developing career management competencies among undergraduates and the role of work-integrated learning. Journal of Teaching in Higher Education, 21(3), 266-286. doi: 10.1080/13562517.2015.1136281

Kementerian Pengajian Tinggi Malaysia. (2010). Modul Kemahiran Insaniah untuk IPT Malaysia. Serdang: Universiti Putra Malaysia.

Kress, G. (2010). Curriculum for the future. Cambridge Journal of Education, 30(1), 133-145. doi: $10.1080 / 03057640050005825$

Lee, H., Parsons, D., Kwon, G., Kim, J., Petrova, K., Jeong, E., \& Ryu, H. (2016). Cooperation begins: Encouraging critical thinking skills through cooperative reciprocity using a mobile learning game. Computers and Education, 97, 97-115. doi: 10.1016/j.compedu.2016.03.006

Leung, L., \& Lee, P. S. N. (2011). The influences of information literacy, internet addiction and parenting styles on internet risks. New Media \& Society. doi: 10.1177/1461444811410406

Lidija, V., Renata, C., \& Sanja, T. V. (2015). Lifelong learning and changes in preschool teacher education: Croatian experiences. Croatian Journal of Education, 17(2), 175 - 189. doi: 10.15516/cje.v17i0.1474

Lindahl, M. G., \& Folkesson, A. M. (2012). Can we let computers change practice? Educators' interpretations of preschool tradition. Computers in Human Behavior, 28(5), 1728-1737. doi: 10.1016/j.chb.2012.04.012

Lunderberg, V.J. (2016). Pedagogical implementation of 21st century skills. Educational Leadership and Administration: Teaching and Program Development, 27, 82-100. Diperoleh daripada https://eric.ed.gov/?id=EJ1094407

Luxon, T., \& Peelo, M. (2009). Internationalisation: Its implications for curriculum design and course development in UK higher education. Innovations in Education and Teaching International, 46(1), 51-60. doi: 10.1080/14703290802646172

McNall, M., Reed, C. S., Brown, R., \& Allen, A. (2009). Brokering community-university engagement. Innovative Higher Education, 33(5), 317-331. doi: 10.1007/s10755-008-9086-8

Misra, S. (2012). Implications of globalization on education. Romanian Journal for Multidimensional Education, 4(2), 69-82. Diperoleh daripada https://papers.ssrn.com/sol3/papers.cfm?abstract_id=1800740

Mortensen, C. J., \& Nicholson, A. M. (2015). The flipped classroom stimulates greater learning and is a modern 21 st century approach to teaching today's undergraduates. Journal of Animal Science, 93(7), 3722-3731. doi: $10.2527 /$ jas.2015-9087

Mtawa, N. N., Fongwa, S. N., \& Wangenge-Ouma, G. (2016). The scholarship of university-community engagement: Interrogating Boyer's model. International Journal of Educational Development, 49, 126133. doi: 10.1016/j.jijedudev.2016.01.007

O'Connor, K. M., Lynch, K., \& Owen, D. (2011). Student-community engagement and the development of graduate attributes. Education and Training, 53(2/3), 100-115. doi: 10.1108/00400911111115654

O'Flaherty, J., \& Phillips, C. (2015). The use of flipped classrooms in higher education: A scoping review. Internet and Higher Education, 25, 85-95. doi: 10.1016/j.iheduc.2015.02.002

Penprase, B. E. (2018). Chapter 9. The fourth industrial revolution and higher education dalam N. W. Gleason (ed.), Higher education in the era of the fourth industrial revolution. doi: 10.1007/978-981-13-0194-0_9

Penttinen, L., Skaniakos, T., \& Lairio, M. (2013). Supporting students' pedagogical working life horizon in higher education. Journal of Teaching in Higher Education, 18(8), 883-894. doi:10.1080/13562517.2013.795936

Petre, C. (2015). The identitary motivation for teaching career. A study on primary and preschool pedagogy students. Procedia - Social and Behavioral Sciences, 180, 937-944. doi: 10.1016/j.sbspro.2015.02.248

Roland Berger (2016). Think act industries 4.0: How the fourth industrial revolution is reshuffling the economic, social and industrial model. Germany. Roland Berger GMBH. Diperoleh daripada https://www.rolandberger.com/en/Publications/The-Industrie-4.0-transition-quantified.html 
Schuwirth, L., \& Ash, J. (2013). Assessing tomorrow's learners: In competency-based education, only a radically different holistic method of assessment will work. Six things we could forget. Medical Teacher, 35(7), 555-559. doi: 10.3109/0142159X.2013.787140

Scott, C. L. (2015). The futures of learning 3: What kind of pedagogies for the 21st century? UNESCO Education Research and Foresight, Paris. [ERF Working Papers Series, No. 15]. Diperoleh daripada http://repositorio.minedu.gob.pe/bitstream/handle/123456789/3747/The\%20Futures\%20of\%20Learning\% 203\%20what\%20kind\%20of\%20pedagogies $\% 20$ for $\% 20$ the $\% 2021$ st $\% 20$ century.pdf?sequence $=1$

Sharma, Y. (2017). Global: Move over Moocs - Collaborative Mooc 2.0 is coming. In: Mihut G., Altbach P.G., Wit H.. (eds). Understanding global higher education. global perspectives on higher education. Sense Publishers, Rotterdam. doi: 10.1007/978-94-6351-044-8_36

Sharon, W. (2018). Impacts of pre-service training and coaching on kindergarten quality and student learning outcomes in Ghana. Studies in Educational Evaluation, 59, 112-123. doi:org/10.1016/j.stueduc.2018.05.001

Smith, L. M., Emmett, H., \& Woods, M. (2008). Experiential learning driving community based nursing curriculum. Rural and Remote Health, 8(3):901. Diperoleh daripada https://www.ncbi.nlm.nih.gov/pubmed/18759536

Soska, T. M., \& Butterfield, A. K. J. (2013). University-community partnerships: Universities in civic engagement. Taylor and Francis. doi:org/10.4324/9780203051283

Sparapani, E. F., Perez, D. C., Gould, J., Hillman, S., \& Clark. L. (2014). A global curriculum? Understanding teaching and learning in the United States, Taiwan, India, and Mexico. SAGE Open. doi: $10.1177 / 2158244014536406$

Speight, S., Lackovic, N., \& Cooker, L. (2013). The contested curriculum: academic learning and employability in higher education. Tertiary Education and Management, 19(2), 112-126. doi: $10.1080 / 13583883.2012 .756058$

Sumsion, J. (2000). Negotiating otherness: A male early childhood educator's gender positioning. International Journal of Early Years Education, 8(2), 129-140. doi:10.1080/09669760050046174

World Economic Forum. (2016). Insight report: The global competitiveness report 2016-2017. Geneva: World Economic Forum. Diperoleh daripada www.weforum.org/gcr

Wrahatnolo, T., \& Munoto. (2018). 21st centuries skill implication on educational system. IOP Conference Series: Materials Science and Engineering, 296. doi:10.1088/1757-899X/296/1/012036 